\title{
A ATUAÇÃO DA MULHER NO SETOR COMERCIAL DA CIDADE DE PAU DOS FERROS (RN)
}

\author{
Lareska Úrsula de Souza Paiva \\ Universidade do Estado do Rio Grande do Norte, Departamento de Geografia, \\ Pau dos Ferros, RN, Brasil \\ lareska.geo.sousa@gmail.com
}

Josué Alencar Bezerra

Universidade do Estado do Rio Grande do Norte, Departamento de Geografia, Programa de Pós-Graduação em Planejamento e Dinâmicas Territoriais no Semiárido

Pau dos Ferros, RN, Brasil josuebezerra@uern.br

\begin{abstract}
RESUMO
O comércio é uma atividade presente nos estudos da Geografia, cada vez mais representativo no sistema produtivo da sociedade contemporânea. Os estudos sobre o comércio, associados a análise da atuação da mulher, não são recorrentes, por este motivo, buscamos investigar a atuação das proprietárias de estabelecimentos comerciais de Pau dos Ferros (RN). Esta cidade aparece como um centro regional que apresenta uma diversidade de estabelecimentos comerciais e de prestação de serviços como shopping, supermercados, galerias, lojas de departamento, instituições de ensino e clínicas médicas. Associamos essa discussão às lutas feministas na conquista pelo seu espaço e na quebra de paradigmas na sociedade, observando as dificuldades em que as mulheres adentrem ao mercado de trabalho em cargos de liderança em seu próprio negócio. Para a efetivação desta pesquisa nos apoiamos em obras que versam sobre os conceitos de comércio e consumo urbanos e gênero. Utilizamos dados secundários extraídos do IBGE e da Secretaria de Tributação de Pau dos Ferros, com o recorte temporal de 10 anos (20082018), bem como a realizamos um trabalho de campo em julho de 2019, mediante a aplicação de formulários de caráter quali-quantitativo com o recorte de investigação. Estudar a atuação da mulher como proprietária desses estabelecimentos comerciais nos fez compreender seu perfil e dificuldades à frente destes estabelecimentos na cidade. Concluímos que mulheres que lutaram e lutam pela sua autonomia, conquistam espaço e abrem o seu próprio negócio em busca de sua independência social. Mulheres que inspiram outras mulheres a também realizam o seu sonho de abrirem o próprio negócio.
\end{abstract}

Palavras-chave: Comércio. Preconceito. Mulher. Pau dos Ferros.

\section{WOMEN'S ACTION IN THE COMMERCIAL SECTOR OF THE CITY OF PAU DE FERROS (RN)}

\begin{abstract}
Commerce is an activity present in geography studies, increasingly representative in the productive system of contemporary society. Studies on commerce, associated with the analysis of women's performance, are not recurrent, so we sought to investigate the performance of owners of commercial establishments in Pau dos Ferros (RN). This city appears as a regional center with a diversity of commercial and service establishments uch as shopping malls, supermarkets, galleries, department stores and government offices, and medical clinics. We associate this discussion with feminist struggles in conquering their space and breaking paradigms in society, noting the difficulties in which women enter the job market in leadership positions in their own business. To carry out this research we rely on works that deal with the concepts of urban commerce and consumption and gender. We use secondary data extracted from IBGE and the Pau dos Ferros Taxation Secretariat, with the 10-year time frame (2008-2018), as well as carry out field work in July 2019, through the application of qualitative and quantitative forms. Studying the role of women as owner of these commercial establishments made us understand their profile and difficulties ahead of these establishments in the city. We conclude that women who fought and fight for their autonomy, conquer space and open their own business in search of their social independence. Women who inspire other women to also fulfill their dream of opening their own business.
\end{abstract}

Keywords: Trade. Preconception. Woman. Pau dos Ferros.

$\begin{array}{lllll}\text { Caminhos de Geografia } \quad \text { Uberlândia-MG } & \text { v. 21, n. } 76 \quad \text { Ago/2020 } & \text { p. 85-97 } & \text { Página } 85\end{array}$




\section{INTRODUÇÃO}

A discussão sobre comércio e gênero no âmbito da Geografia não nos parece comum em trabalhos de investigação científica. Segundo Silva (2014a), no que diz respeito especificamente a discussão sobre o comércio e consumo urbanos, parte dos investigadores veem este tema como algo banal, sem importância para a pesquisa científica. De acordo com o autor (ld.), demonstra-se um preconceito em sua compreensão em confusão com o senso comum, pois, as atividades comerciais se apresentam como aquelas cada vez mais presentes no cotidiano das pessoas das cidades.

Muitas publicações que utilizam o tema do comércio e do consumo na Geografia acabam por não problematizar e explicar o processo de produção do espaço geográfico por não recorrerem a métodos que subsidiem uma análise crítica do espaço, ficando, por vezes, em constatações corriqueiras vinculadas aos discursos hegemônicos das empresas do setor ou mesmo fazendo trabalhos onde o fator locacional seja o objeto principal da pesquisa e não superam a localização enquanto meio de analise Geográfica (SILVA, 2014a, p. 152).

O estudo sobre comércio e consumo está ligado a Geografia Urbana no qual pesquisas realizadas contribuem para ampliar a reflexão sobre este tema e a organização dos espaços das cidades, sendo o lucro e a reprodução do capital fundamentais na reprodução da sociedade capitalista, bem como o estudo sobre as formas e práticas espaciais urbanas advindas da atividade comercial (SILVA, 2014a; CORRÊA, 1989).

Não apenas sob o regime capitalista, mas ao longo de toda a história da cidade, a mulher sempre apareceu com um papel importante na revolução da sociedade (MUMFORD, 1998), embora não tenhamos observados estudos na Geografia que associem esse debate com o comércio. As discussões encontradas em artigos ou em trabalhos diversos têm o gênero como temática mais presente, embora este conceito seja mais denso e delicado de ser tratado. Assim, parece-nos mais comum este debate no campo da Administração, Filosofia e Ciências Sociais.

Dessa forma, nos perguntamos por que o comércio e a figura da mulher não aparecem interligados em uma construção de estudos de investigação científica? Esse questionamento surgiu como uma pergunta de partida para nossa pesquisa ${ }^{1}$. O interesse nesta temática também vem com as leituras ligadas a formação política de cunho feminista e a observação empírica do objeto de estudo.

Para a consecução desta pesquisa, elegemos o estudo do comércio como fenômeno modelador do espaço, apoiado em autores como Cachinho e Salgueiro (2009), Pintaudi (2009) e Silva (2014a); a discussão acerca da produção do espaço urbano, em que nos apoiamos principalmente em Corrêa (1989), e sobre nosso objeto empírico de estudo, visitamos as obras de Barreto (1987), Dantas (2014), Silva (2014a) e Bezerra (2016). A leitura sobre a mulher, consideramos as obras de Pereira, Santos e Borges (2005), Abramo (2007), Assis (2009), Gonçalves e Miranda (2012) e Rodrigues (2019).

O presente trabalho propõe analisar a atuação da mulher como proprietária de seu estabelecimento comercial na cidade de Pau dos Ferros, com a análise do seu quantitativo no recorte de 10 anos (2008 a 2018) permitindo, assim, realizarmos uma leitura acerca da participação da mulher como agente atuante nos estabelecimentos comerciais da cidade de Pau dos Ferros, na condição de proprietária de seu negócio.

O município de Pau dos Ferros está localizado na porção Oeste do Rio Grande do Norte, e abriga cerca de 30.394 mil habitantes, de acordo com a estimativa do Instituto Brasileiro de Geografia e Estatística (IBGE, 2019), se apresentando como principal centro regional, por sua importância e na prestação de serviços especializados nas áreas da educação superior, saúde, financeiros e por sua variedade de estabelecimentos comerciais (DANTAS, 2014; BEZERRA, 2016).

Nesse contexto, a mulher aparece como importante agente na modificação do espaço da cidade, visto sua ocupação nas atividades comerciais. O que antes era visto somente em seu ambiente de casa, do lar, agora elas também começam a priorizar além da sua vida financeira, sua educação e especialização no mercado.

De acordo com Rodrigues (2019), mulheres e homens ocupam papeis na sociedade e, por essa razão, constituem intervenções que servem para ser objeto de pesquisa. A mulher em sua história, inicialmente

\footnotetext{
1 Torna-se importante frisar que desenvolvemos pesquisas com financiamento do CNPq (bolsa de estudo), no âmbito do Núcleo de Estudos em Geografia Agrária e Regional da UERN, que versam sobre os estudos do comércio e consumo urbanos na cidade de Pau dos Ferros (RN). Observar em Paiva e Bezerra (2018) o resultado de uma destas pesquisas.
}

\begin{tabular}{lllll}
\hline Caminhos de Geografia $\quad$ Uberlândia-MG & v. 21, n. $76 \quad$ Ago/2020 & p. 85-97 & Página 86
\end{tabular}


vista como um ser feito para a procriação, se mostrando como uma discriminação, coloca a mulher subordinada ao homem, o mesmo, sendo visto como o dono do saber e a mulher restrita aos serviços domésticos e a família. Segundo Rodrigues (2019):

\begin{abstract}
Um processo que envolve quebra de paradigmas, revisões e conceitos e novas formas de agir e pensar, mudança de mentalidade e comportamento e tento conflituoso. Ideia, conceitos e valores, enraizados por séculos em uma sociedade não desaparecem de um momento para o outro (RODRIGUES, 2019, p. 06).
\end{abstract}

A importância das lutas do movimento feminista, segundo Rodrigues (2019), surge inicialmente nos Estados Unidos nos anos 1960 e se expande pelo Ocidente. Ao longo do século XX o movimento já havia se espalhado pelo mundo e manifestações como "queima de sutiãs" em praça pública e gritos de liberdade eram ouvidos por toda parte do mundo.

No Brasil esse movimento ganha força no ano de 1972 na cidade de São Paulo, por um grupo organizado de mulheres que espalhava em debates e fóruns, temas sobre feminismo e, dessa maneira, ganharam mais força embora, ao mesmo tempo, se mostrou como um movimento criticado pelos tradicionais e não acostumados com mulheres gritando por liberdade e direitos. Esses movimentos iniciais foram muito importantes para que as mulheres pudessem conhecer mais a fundo as demandas femininas que lutavam pela igualdade e liberdade (Id.).

Segundo Pereira (2005), a representação de mulheres se inserindo no mercado de trabalho tem aumentado consideravelmente nos últimos anos, mas o aumento desta participação não significa diminuição da discriminação de gênero da mesma no trabalho e em casa pela sociedade.

Isso posto, esta pesquisa propôs analisar a atuação da mulher à frente dos estabelecimentos comerciais sediados em Pau dos Ferros, observando algumas características socioeconômicas e principalmente sua atuação no setor comercial na cidade. Para isso, realizamos um levantamento da participação das mulheres proprietárias dos estabelecimentos comerciais criados no período de 10 anos (2008 a 2018) e os ramos de atividade destes estabelecimentos que a mulher comanda. As mulheres, aos poucos, vêm conquistando o seu espaço, ganhando autonomia financeira e abrindo o seu próprio negócio.

Para estruturação deste trabalho, o organizamos em cinco seções sendo a primeira esta denominada Introdução; a seguir temos a Metodologia, momento em que apresentaremos como a pesquisa foi realizada; a seção três tratará da caracterização do objeto empírico da pesquisa e é intitulada por Uma breve apresentação de Pau dos Ferros e sua relação com o comércio; a quarta seção tratou da A inserção da mulher no mercado de trabalho e as dificuldades encontradas; e, em seguida, a seção cinco chamada de $\mathrm{A}$ atuação da mulher proprietária do comércio na cidade de Pau dos Ferros ( $\mathrm{RN}$ ) e, por fim, as Considerações Finais.

\title{
METODOLOGIA
}

Para a realização desta pesquisa seguimos o enfoque quali-quantitativa na seleção e levantamento dos dados secundários e primários. Baseado nas leituras de Goldenberg (1997), esta opção metodológica contribui para a compreensão da pesquisa no que tange sua associação com dados estatísticos e o levantamento bibliográfico que a natureza desta pesquisa exige.

A pesquisa se iniciou com leituras e discussões de textos teóricos que versaram sobre o tema, como Corrêa (1989), que contribuiu para a compreensão da produção do espaço urbano; em Silva (2014a), acerca de estudos sobre o comércio e consumo urbanos, que foca nas formas do comércio ${ }^{2}$ e o consumo ligados à cidade; Bezerra (2016), que contribuiu para a compreensão da configuração urbano-regional de Pau dos Ferros e uma maior caracterização do fenômeno estudado; e Dantas (2014), que igualmente estuda Pau dos Ferros, em uma perspectiva da estruturação econômica da cidade.

Ferreira e Bezerra (2017) ajudaram na compreensão do processo de modernização das práticas do comércio urbano e a tentativa de se inovar, atraindo mais pessoas para o consumo no âmbito de Pau dos Ferros; Cachinho e Salgueiro (2009) e Pintaudi (2002), que tratam dos espaços dinâmicos de evolução e modelos interpretativos, a relação da cidade com o comércio, e como este tem sua importância no próprio crescimento da cidade, inovando, mudando o estilo de vida das pessoas e transformando estes espaços; e

\footnotetext{
2 Torna-se importante frisar que os estudos sobre o comércio na Geografia podem abordar uma diversidade de possibilidades de dimensões no espaço e que a informal, por exemplo, é uma das mais importantes na leitura da cidade e do urbano, embora não tenhamos abordado neste artigo. Sobre a as expressões da informalidade na via pública em Pau dos Ferros (RN) ver o trabalho de Silva (2014b).
}

$\begin{array}{lllll}\text { Caminhos de Geografia } \quad \text { Uberlândia-MG } & \text { v. 21, n. } 76 \quad \text { Ago/2020 } & \text { p. 85-97 } & \text { Página } 87\end{array}$


Barreto (1987), que versa sobre a formação do espaço de Pau dos Ferros, e sua ligação originária como um espaço comercial.

Para o entendimento sobre a mulher na sociedade e sua aproximação com o debate sobre o comércio, consultamos Abramo (2007), que discorre sobre a compreensão do gênero feminino no mercado de trabalho e como ocorre a sua desvalorização no mercado por ser vista como uma mão de obra secundaria; Gonçalves e Miranda (2012) sobre as manifestações da mulher em busca da aceitação no trabalho fora de casa e os avanços e as conquistas femininas, frente as severas discriminações no ambiente de trabalho.

Pereira, Santos e Borges (2005), ajudaram no debate sobre a mulher no mercado de trabalho, e o entendimento do processo em que a mulher consegue autonomia financeira e liberdade da sua própria vida; consultamos Assis (2009) e Rodrigues (2019) que contribuíram no debate da importância da mulher na sociedade e suas lutas na quebra de paradigmas enraizados por séculos na sociedade.

Após a etapa de levantamento bibliográfico, realizamos uma exaustiva etapa de coleta de dados na Secretaria Municipal de Tributação de Pau dos Ferros, sobre o quantitativo de estabelecimentos comerciais sediados na cidade no período elencado da pesquisa. Este levantamento foi realizado pelo total de estabelecimentos comerciais cadastrados no município, por sexo do proprietário, localização e segmento do comércio. A dificuldade no levantamento destes dados se deu devido a não disponibilidade, de início, dos dados que identificasse o sexo/nome dos proprietários. Para isso, deixamos documento oficial nos comprometendo com o sigilo na utilização destes dados.

A partir do levantamento e tabulação dos dados sobre os estabelecimentos comerciais sediados em Pau dos Ferros, identificamos um total de 232, considerando os criados ao longo dos 10 anos pesquisados (2008-2018). Observando a metodologia adotada, selecionamos o mínimo de $10 \%$ desse total de pontos comerciais cadastrados em Pau dos Ferros para aplicação dos formulários com questões semiabertas, em que foram entrevistadas ${ }^{3}$ mulheres proprietárias desses estabelecimentos.

De início, este mínimo de formulários foi estabelecido como meta na pesquisa de campo, porém, com a possibilidade de ampliação deste número conforme a regularidade na resposta e a dificuldade no acesso aos entrevistados, considerando a metodologia adotada na pesquisa. Quando da realização desta etapa, a dificuldade em localizar os estabelecimentos a partir do endereço disponível no cadastro municipal e, principalmente, a difícil recepção destas proprietárias para realização das entrevistas, prolongou a conclusão do trabalho, e o atendimento do mínimo de entrevistas estipuladas.

O formulário de pesquisa iniciava-se com perguntas de identificação do entrevistado e estabelecimento, tais como: idade, naturalidade, cidade de residência, número de funcionários. Logo em seguida, o formulário se divide em 04 perguntas fechadas e 04 abertas. Das perguntas fechadas: nível de escolaridade; se tinha filhos; estado civil; os ramos de atividade do estabelecimento. Quanto as perguntas abertas: qual vínculo com o estabelecimento; se o/a parceiro/a interferia em seu trabalho; Se conseguia ter lazer nas horas em que não estava trabalhando; Qual seria a maior dificuldade encontrada em sua carreira profissional.

O campo foi o momento possível para conhecer as mulheres que estão à frente de seu empreendimento na cidade e mediante o instrumento de pesquisa, com um roteiro de perguntas, pudemos extrair melhor a atuação destas neste importante setor da economia urbana.

Como procedimento metodológico, também elaboramos um mapa com o software QGIS, versão 3.8.3, para a localização geográfica de Pau dos Ferros, bem como para espacializar a localização dos pontos comerciais abordados durante a pesquisa de campo. Utilizamos imagens fotográficas destes estabelecimentos para ilustrar sua morfologia na cidade neste último mapa. O trabalho de campo foi realizado em 04 dias no mês de julho de 2019.

É com base nas leituras, coleta de dados primários e secundários que foi possível uma melhor compreensão da atuação da mulher frente o comércio e as dinâmicas do espaço urbano na cidade de Pau dos Ferros.

\section{PAU DOS FERROS E SUA RELAÇÃO COM O COMÉRCIO}

Como parte das cidades interiorizadas do Nordeste brasileiro, a formação territorial de Pau dos Ferros está associada a atividade de criação de gado (ANDRADE, 2004). Segundo Barreto (1987) e Andrade

\footnotetext{
3 Esta pesquisa está registrada no Conselho de Ética de Pesquisa (CEP), junto a Plataforma Brasil, sob o número 19222919.0.0000.5294. Ver: http://plataformabrasil.saude.gov.br/
} 
(2004), no local que esta cidade cresceu se dava um trecho de passagem das boiadas, conhecidas com caminhos de gado, que seguiam o curso dos principais rios da região, como o Apodi-Mossoró.

Os comboios eram responsáveis por levar e trazer mercadorias para comercializar, o que mostra desde sua origem, o comércio existindo com a expansão por consequência do ciclo do gado, dando origem ao povoamento da região. Entretanto, somente em 1856, Pau dos Ferros passa à categoria de Vila, reivindicação há bastante tempo requerida pela população local que não encontrava em Portalegre, sede administrativa de praticamente toda região, a atenção na oferta de serviços básicos para sua população (BEZERRA; 2016). Somente em 02 de dezembro de 1924, Pau dos Ferros foi elevada à categoria de cidade (BARRETO, 1987).

Nas últimas décadas do século passado, Pau dos Ferros surge como um centro regional importante no Rio Grande do Norte, abrigando diversos tipos de estabelecimentos comerciais e serviços especializados que, segundo Bezerra (2016), mostrou que esta cidade:

[...] abriga os estabelecimentos comerciais mais diversos, além de ofertar serviços especializados disponíveis apenas nos grandes centros regionais da região. Os produtos e serviços que mais se destacam são do gênero vestuário, alimentício, calçados, eletroeletrônico e móveis; os serviços ligados principalmente à saúde, materializados pelas clínicas médicas, laboratórios, e hospital; e na educação, com os campi universitários, as faculdades privadas e escolas técnicas, o que revalida seu papel de centro urbano mais importante da região (BEZERRA, 2016, p. 219-220).

A centralidade urbana exercida por Pau dos Ferros está relacionada à sua disposição espacial de comando de uma região composta por vários pequenos municípios com pouca diversidade econômica e baixo número de habitantes (IBGE, 2019), característica comum de sua área de influência (Figura 01).

De acordo com o IBGE (2019), Pau dos Ferros possui uma população total estimada em 30.394 habitantes, destes, $92,03 \%$ é considerada urbana. Seu tamanho é pequeno se comparado às duas maiores cidades do Rio Grande do Norte - quase 29 vezes menor que Natal e menos de $11 \%$ do tamanho de Mossoró (BEZERRA, 2016; IBGE, 2019).

Mesmo com essa dimensão, observamos a importância da cidade de Pau dos Ferros em relação as cidades menores da região, justamente por se tratar de uma cidade com uma diversidade de produtos comercializados e serviços prestados que, segundo Dantas (2014), coloca Pau dos Ferros como um polo regional cuja importância é apresentada em suas atividades comerciais e de prestação de serviços especializados em educação, saúde e finanças.

Figura 01 - Mapa de localização do município de Pau dos Ferros, RN, Brasil.

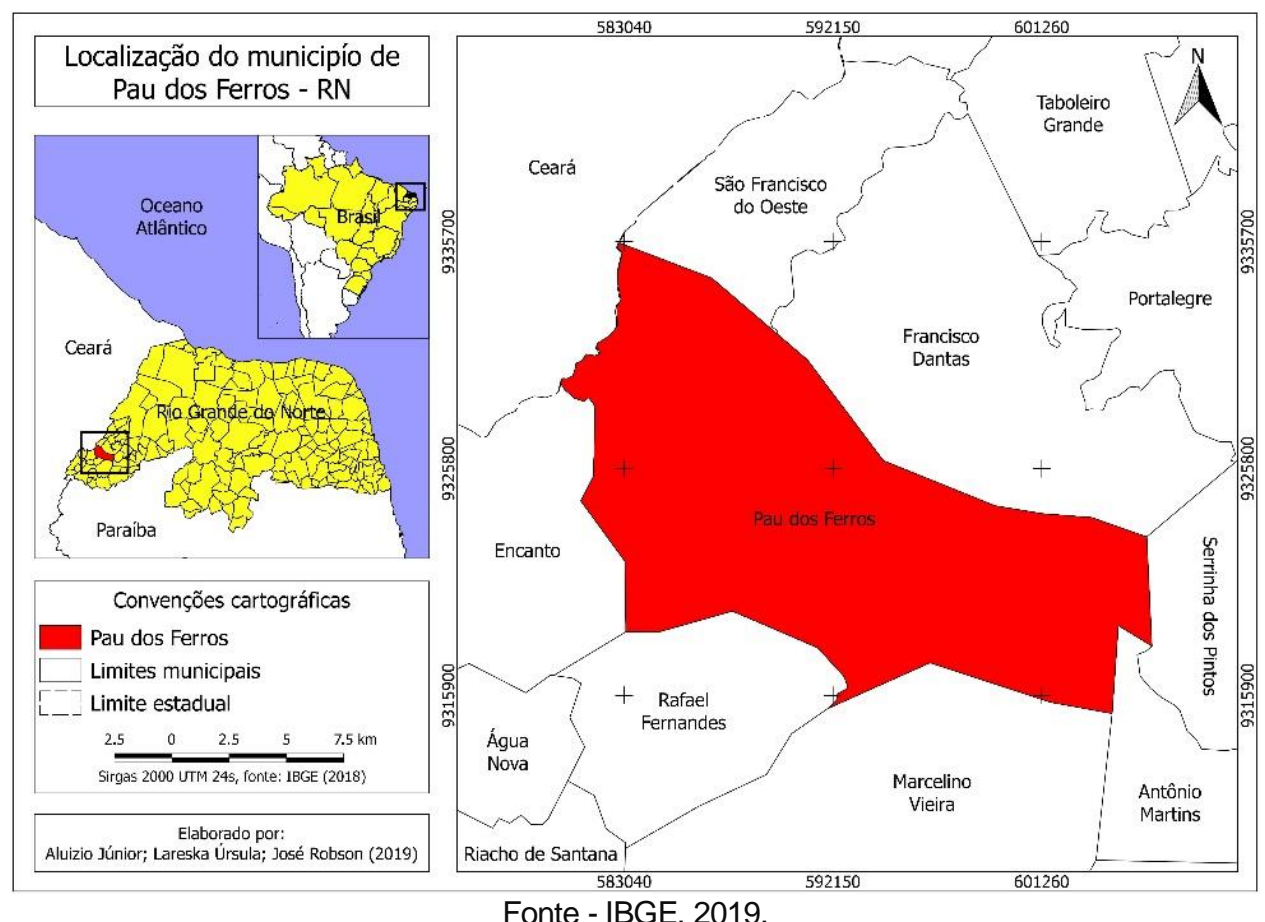

Fonte - IBGE, 2019 
Sobre essa realidade vista nas cidades com esse perfil comercial, como em Pau dos Ferros, segundo Salgueiro e Cachinho (2009), as estruturas comerciais e as cidades sofreram transformações na metade do século XX, com o desenvolvimento da industrialização, em que a lógica do mercado e a organização da produção tayloristas e fordistas invadem diretamente a vida social e das espacialidades, onde se inclui a organização urbana, modificando o espaço, para facilitar a produção industrial e a reprodução da força do trabalho.

O aumento do poder de compra da população e uma maior mobilidade dos consumidores favorece, de início, o comércio fixo. Com isso, cresce consideravelmente o número de estabelecimentos comerciais, ganhando novos formatos com armazéns e cooperativas operarias, ajudando a configurar o centro da cidade capitalista e, em seguida, surgindo uma hierarquia sobre o centro principal (CORRÊA, 1989). É a partir do aglomerado e da área de influência na área central que vai crescer o mundo dos estabelecimentos e de suas funções comerciais da cidade (CACHINHO; PINTAUDI; 2009). E como enxergamos esse fenômeno com a presença da figura da mulher no mercado de trabalho? Muitas representações espaciais estão associadas à sua participação nesse processo.

\section{A INSERÇÃO DA MULHER NO MERCADO DE TRABALHO E AS DIFICULDADES ENCONTRADAS}

A mulher tem tradicionalmente nas sociedades ocidentais o papel de esposas e donas de casa, enquanto o trabalho e sustento da casa eram restritos aos homens. Mas com a necessidade econômica, após a revolução industrial, mais precisamente no século XX, as mulheres começaram a trabalhar inicialmente de maneira informal, como dar aulas de piano, confecção de doces para vender fora ou até mesmo bordados por encomenda, entre outros artifícios, na tentativa de conquistar a independência financeira e, assim, contribuir economicamente em casa.

De acordo com Assis (2009), foi a partir das lutas contra o preconceito de gênero, discriminações e lutas constantes por seu espaço, que se deram as conquistas femininas no Brasil, tais como: do direito ao voto sem restrições para todas as mulheres em 1932; o direito ao divórcio em 1977; a inserção ao mercado de trabalho em ocupações de nível superior de modo formal, nos anos 1980; e a ampliação da licença maternidade, somente no ano de 2008.

Ainda, segundo Assis (2009), as mulheres estão inseridas no mercado de trabalho além de colaboradoras, mas, também como líderes, e com a capacidade de liderança. A partir da crescente urbanização e consequente expansão da industrialização que as mulheres adentrarem no mercado de trabalho, período também marcado pelo preconceito de gênero e salário inferior ao dos homens para exercerem as mesmas funções no trabalho, característica, ainda, presente nos dias atuais ${ }^{4}$.

De acordo com Oliveira (2012), a mulher não tinha permissão para trabalhar fora, vistas apenas como donas de casas e esposas, já que, para elas, não existia a possibilidade de estudar e trabalhar sem o consentimento dos esposos ou pais, uma vez que exigia a necessidade de sair de casa e deixarem as atividades domésticas. Foi através de muita luta por seus direitos que atualmente observamos as mulheres não somente como empregadas no setor produtivo, mas também como colaboradoras e chefes de empresas, ou de seu próprio negócio.

Segundo Pereira (2005), as porcentagens de mulheres se inserindo no mercado de trabalho e economicamente atuando nele tem aumentado consideravelmente, mas esse crescimento não significa diminuição da discriminação de gênero da mesma no trabalho, em casa e pela sociedade.

Os salários das mulheres brasileiras são cerca de $25 \%$ menores do que os homens para a mesma jornada de trabalho e com o mesmo nível educacional. As mulheres estão pouco representadas nos estratos de salários altos. Em contrapartida, elas predominam nos estratos de salários mais baixos (PEREIRA, SANTOS, BORGES, 2005, p. 06).

Atualmente, as empresas buscam ter mulheres nas equipes de colaboradores, por verificarem nelas requisitos de flexibilidade, intuição e a capacidade de trabalho em equipe e sensibilidade (ASSIS, 2009).

\footnotetext{
${ }^{4}$ De acordo com pesquisa do IBGE (2019), sobre a participação da mulher no mercado de trabalho, em 2018, as mulheres representavam $45,3 \%$ da força de trabalho, ganhavam $79.5 \%$ do total do salário pago ao homem e tinham uma jornada semanal de trabalho menor em 4,8 horas, sem considerar o tempo dedicado a afazeres domésticos e cuidados de pessoas. Ver reportagem completa em: http://agenciabrasil.ebc.com.br
} 
E como se dá a inserção da mulher no mercado de trabalho? Não é de hoje que os homens dominam os lares e as mulheres não poderiam ter seu próprio dinheiro. Na primeira e segunda guerras mundiais, as quais os homens precisaram ir para as batalhas, as mulheres assumiam os negócios que eram funções masculinas. O resultado das guerras foram muitos homens mortos em campo e outros retornam impossibilitados de exercer as mesmas atividades, tendo a necessidade de a mulher assumir a tarefa exercida por eles e/ou sair de casa para trabalhar (Id.).

No Brasil, a mão de obra feminina ganha força no mercado com a constituição de 1932, que permite a mulher trabalhar com o salário igual ao dos homens, porém, a possibilidade das mulheres grávidas em quatro semanas antes e depois do parto serem demitidas (ASSIS, 2009, p. 04-05).

Desse modo, no século $X X$ as mulheres foram aceitas para trabalhar na operação das máquinas nas fábricas, por se tratar de uma mão de obra barata e também por desempenharem funções repetitivas com mais rapidez e agilidade. Segundo Gonçalves e Miranda (2012), não é que as mulheres tenham deixado de ser donas de casas, mas adentrar no mercado de trabalho possibilitou a sua independência financeira, embora continuassem donas de casa, com duplas ou triplas jornadas de trabalho, assumindo a função de mãe, tendo na prática seu salário bem inferior ao do homem. Não podemos esquecer também que:

A modernização tecnológica em andamento, poupadora de trabalho, cria as bases para reestruturar a produção de bens e serviços, os processos e a organização do trabalho. Suas repercussões na composição orgânica do capital pela tecnificação leva, em maior escala, à exclusão de mulheres, de pessoas idosas e prematuramente idosas e de jovens que deveriam estar entrando no mercado de trabalho (ROSSINI, 2002, p. 48) ${ }^{5}$.

Apenas após a promulgação da constituição brasileira de 1988, que foi consolidada a situação plena de igualdade entre os homens e mulheres, destinando as mulheres o direito de trabalhar e serem donas do seu próprio negócio (GONÇALVES e MIRANDA; 2012, p. 02).

Com essas reflexões que Assis (2009), Gonçalves e Miranda (2012) nos mostram o quão a participação da mulher no mercado contribuiu para a sua liberdade financeira, e como as lutas constantes por seu espaço foram significantes, transformando não somente as suas vidas, mas a estrutura familiar e de todas as mulheres posteriores, bem como a forma como as cidades são produzidas. As mulheres conquistaram autonomia de vida, de seus corpos e de seu sustento, permitindo que as lutas nos movimentos sociais pudessem garantir direito nas próximas gerações.

Sobre o assunto, Abramo (2007) coloca ser possível identificar, mesmo com as lutas por seu espaço, que no mercado de trabalho as mulheres continuam ganhando menos que os homens, com evidenciamos na pesquisa do IBGE (2019), e mesmo que os números de mulheres empregadas sejam inferiores ao número de homens, pode-se perceber um aumento significativo no decorrer dos anos:

Entre 1970 e 1980, enquanto o volume de homens empregados aumentava 5,7\% ao ano, o número de mulheres aumentava $8,2 \%$. Como resultado desse incremento, a participação feminina nesse setor passou de $20 \%$ para $23 \%$. Segundo os dados dos censos demográficos, o número de mulheres empregadas na indústria aumentou $181 \%$ ao longo da década, o que representa o dobro tanto da taxa de crescimento da atividade feminina em geral (95\%), como da incorporação da mão-de-obra masculina à indústria (91\%) (HUMPHREY, 1987 apud ABRAMO, 2007, p. 66).

A participação das mulheres vai modificar suas ocupações, mudando a qualidade do trabalho. $O$ que antes era visto somente a mulher em seu ambiente de casa, do lar, agora elas também começariam a priorizar além da sua vida financeira, a sua educação e especialização no mercado.

O trabalho da mulher estava se universalizando e na década de 1960, as mulheres jovens e solteiras se inseriram no mercado de trabalho. Atualmente, mais de 30 milhões de mulheres trabalham fora de casa no Brasil, em que "[...] cerca de $50 \%$ estão no comércio, serviços e administração; $22 \%$ estão na agricultura; $16 \%$ na área social; $9 \%$ na indústria e 3\% em outros setores" (PEREIRA, SANTOS e BORGES, 2005, p. 06).

\footnotetext{
${ }^{5}$ Atualmente existem uma produção geográfica importante no Brasil, com diferentes caminhos de estudo acerca da questão do gênero. Como exemplo, destacamos as obras da Profa. Dra. Rosa Ester Rossini, autora de diversos estudos nesse campo.
}

$\begin{array}{lllll}\text { Caminhos de Geografia } \quad \text { Uberlândia-MG } & \text { v. 21, n. } 76 \quad \text { Ago/2020 } & \text { p. 85-97 } & \text { Página } 91\end{array}$




\section{A ATUAÇÃO DA MULHER PROPRIETÁRIA DE COMÉRCIO NA CIDADE DE PAU DOS FERROS (RN)}

A participação da mulher no comando dos negócios na cidade tem sido bastante representativa, seguindo a tendência da abertura e pluralismo social visto nas sociedades ocidentais na última década.

De acordo com os dados coletados na Secretaria de Tributação de Pau dos Ferros, verificamos o número de estabelecimentos comerciais criados e liderados por mulheres podendo, assim, compreender a partir desses, a atuação da mulher como proprietária de seu negócio. No gráfico 01 , podemos verificar o quantitativo dos estabelecimentos comerciais criados no período, tendo as mulheres e homens como proprietários de seus empreendimentos.

Com base nos dados, podemos perceber o quantitativo de estabelecimentos criados no período (20082018) na cidade de Pau dos Ferros, no qual uma crescente presença de mulher empreendedora de seu negócio. A partir do ano de 2011 as mulheres aparecem como as que mais abriram estabelecimentos na cidade.

Em detalhe, temos no ano de 2009, a mulher proprietária em 19 e o homem em 14 estabelecimentos; já no ano de 2011 há um total ainda maior de mulheres na posição de proprietária, com 41 estabelecimentos criados, enquanto os homens aparecem com apenas 25. A partir daí, nos os anos seguintes (2011-2018) as mulheres continuam a frente, com o maior número de proprietárias do comércio local. Dessa maneira, a presença da mulher proprietária de seu próprio negócio na cidade de Pau dos Ferros é bastante representativa. No gráfico 02 , podemos identificar o quantitativo total de estabelecimentos de todos os anos analisados.

Gráfico 01 - Pau dos Ferros: evolução do número de estabelecimentos comerciais criados de propriedade de mulheres e homens na cidade (2008-2018).

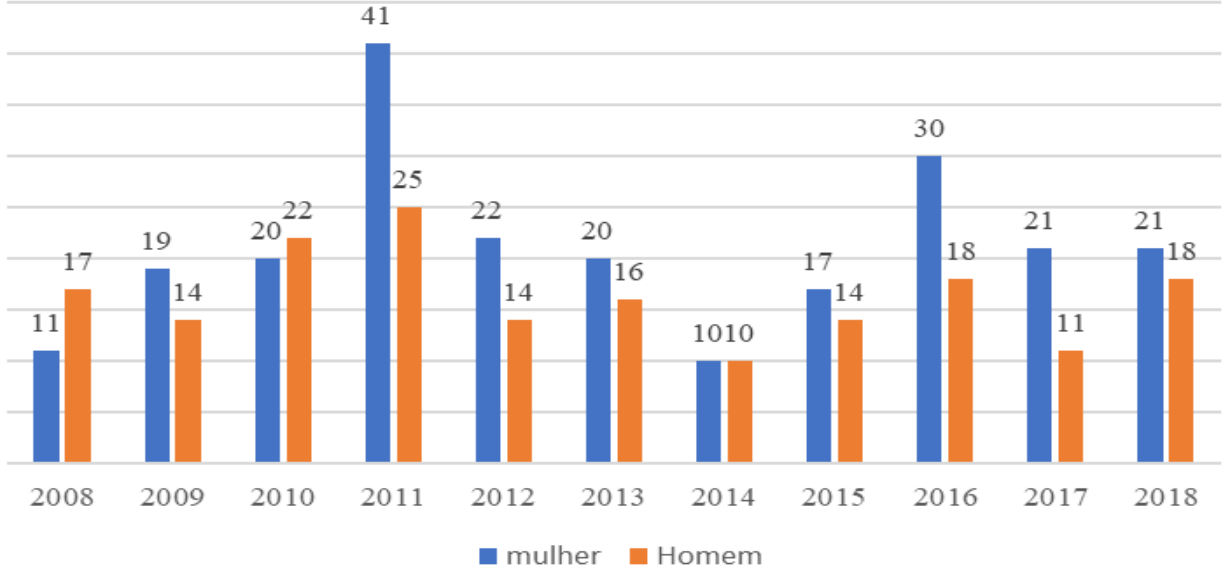

Fonte - Secretaria de Tributação do município de Pau dos Ferros, jun. 2019.

Gráfico 02 - Pau dos Ferros: percentual do total de estabelecimentos comerciais de propriedade de mulheres e homens na cidade (2008-2018).

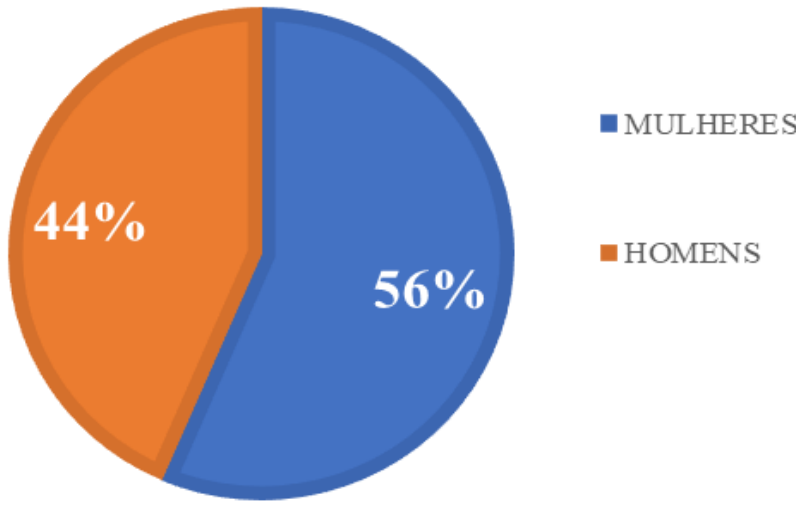

Fonte - Secretaria de Tributação do município de Pau dos Ferros, jun. 2019.

$\begin{array}{lllll}\text { Caminhos de Geografia } \quad \text { Uberlândia-MG } & \text { v. 21, n. } 76 & \text { Ago/2020 } & \text { p. 85-97 } 92\end{array}$


Com a soma de todos os anos analisados de estabelecimentos criados (2008-2018), o número total de mulheres proprietárias de seu estabelecimento comercial na cidade de Pau dos Ferros chega à 232 (56\%), enquanto os homens, com 179 (44\%) estabelecimentos nos quais são proprietários. Para a aplicação dos formulários, utilizamos como meta inicial entrevistar $10 \%$ do total dos estabelecimentos em que as mulheres eram proprietárias, o que totaliza 24 entrevistadas.

Segundo Dantas (2014) e Bezerra (2016), os estabelecimentos comerciais na cidade de Pau dos Ferros são caracterizados por vender roupas, calçados, utensílios domésticos, acessórios para celular, artigos para festa, brinquedos, artigos para salão de beleza, entre outros. E, de acordo com a tabela 01, podemos verificar entre os anos de 2008 a 2018, os ramos de atividade desses estabelecimentos, tendo a mulher como proprietária.

De acordo com os dados coletados, podemos identificar o elevado número de estabelecimentos de vestuário e acessórios, chegando a ter 10 estabelecimentos criados em cada ano de 2011 e 2012 nessa tipologia. A segunda tipologia com maior número no ano de 2011 é do gênero alimentício, que se baseia em estabelecimentos comerciais dos tipos: loja conveniência, mercadinhos e supermercados e bomboniere.

Podemos perceber, também, com base em Bezerra (2016), Dantas (2014) e Ferreira e Bezerra (2017), que Pau dos Ferros se mostra como uma cidade referência no setor, que vem ganhado mais destaque pelo número de estabelecimentos comerciais e prestadores de serviços especializados criados na última década, não se detendo somente a população local, mas, atraindo consumidores de cidades vizinhas que não possuem serviços e comércios diversificados.

E nos registros das figuras 02 e 03, identificamos a diversidade no ramo de atividade dos estabelecimentos comerciais na cidade de Pau dos Ferros, como mulheres proprietárias.

Figura 02 - Pau dos Ferros: loja de artigos de beleza e higiene pessoal.

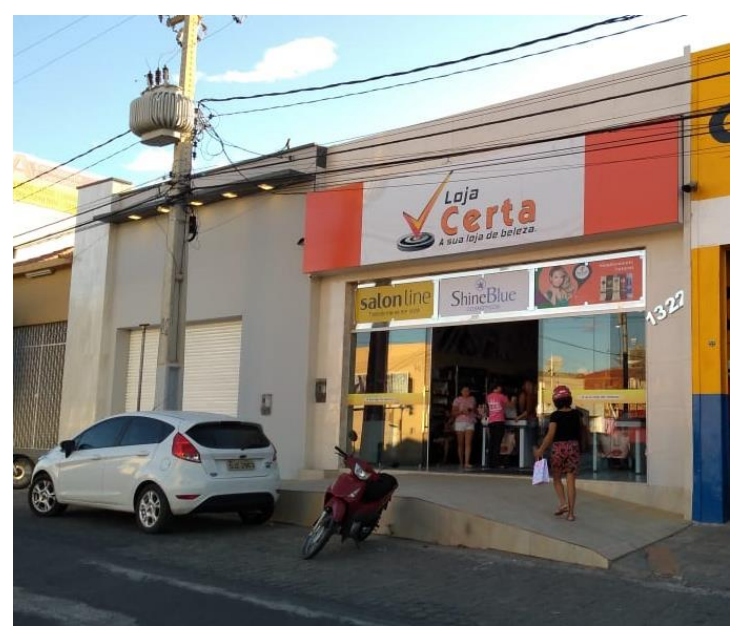

Fonte - Trabalho de campo dos autores, ago., 2019.
Fotos 03 - Pau dos Ferros: loja de confecções de venda no atacado.

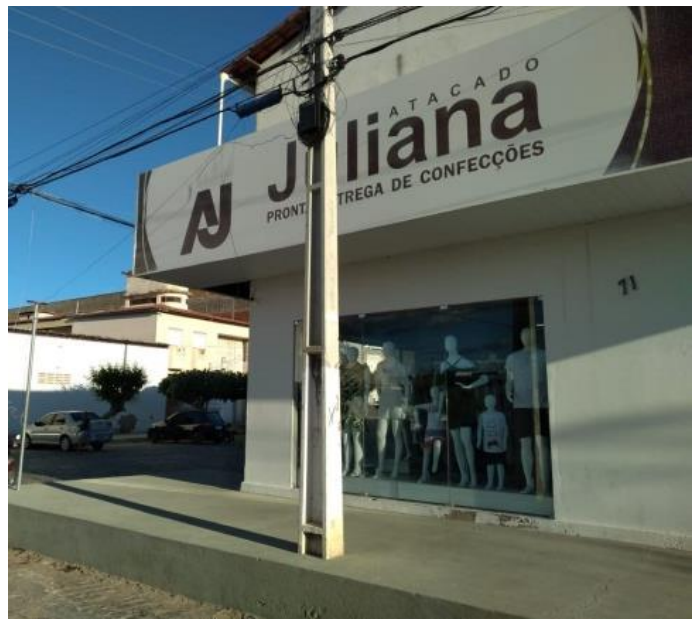

Fonte - Trabalho de campo dos autores, ago., 2019.

Analisando os dados disponibilizados pela Secretaria de Tributação de Pau dos Ferros, podemos perceber a diversidade nos ramos de atividade dos estabelecimentos comerciais, tendo a mulher como proprietária. Considerando a aplicação dos 24 formulários no campo, estes se concentraram na área central da cidade, localização do maior número de estabelecimentos comerciais da cidade. De acordo com a figura 04 , podemos identificar as 08 ruas que tiveram os formulários aplicados nos comércios de cada rua apresentada. 
Figura 04 - Pau dos Ferros: localização das ruas e comércios que tiveram os formulários aplicados.

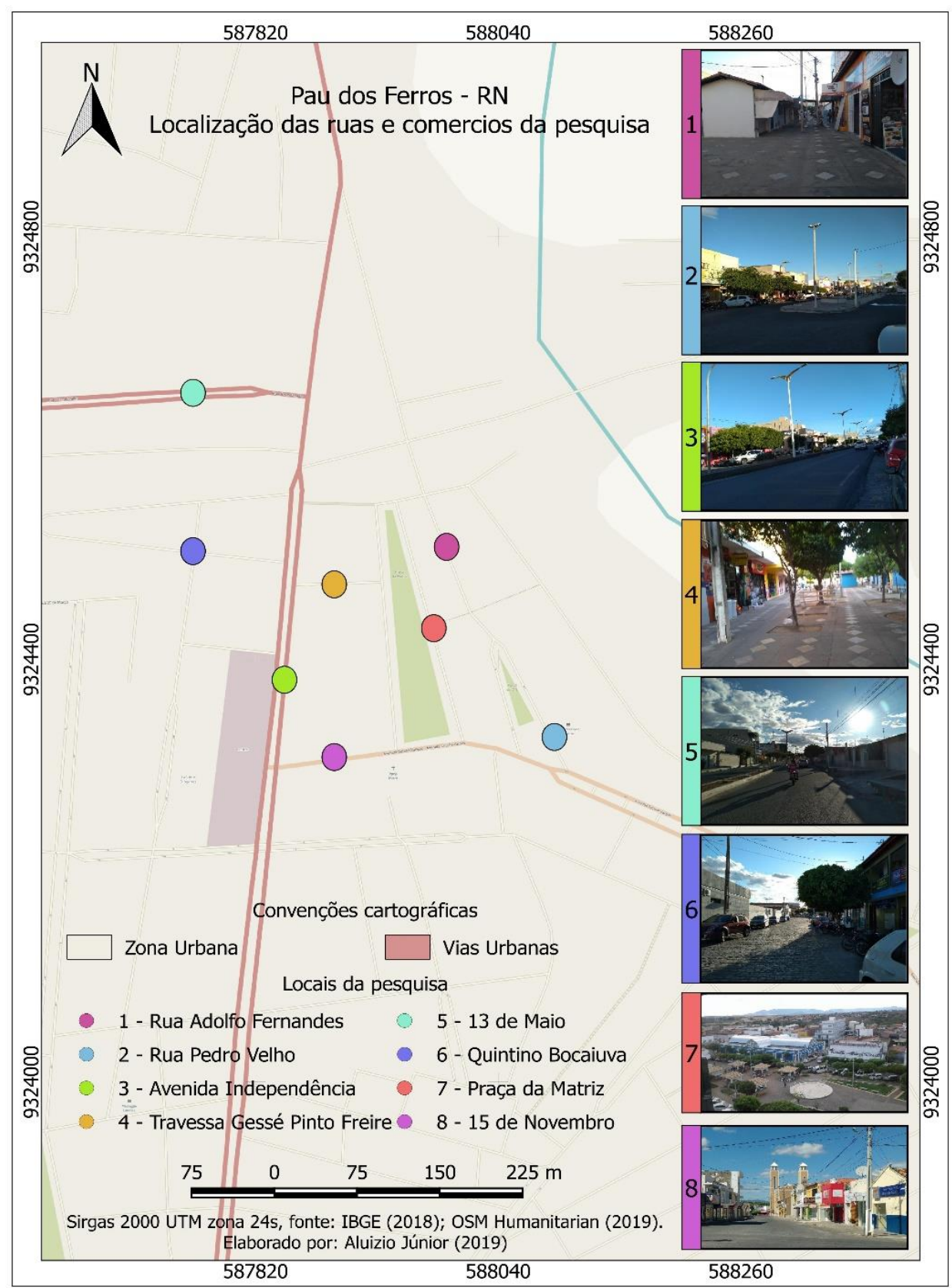

Fonte - Trabalho de campo dos autores, ago., 2019.

Os formulários foram aplicados em estabelecimentos que tem a mulher como proprietária do estabelecimento, e a aplicação dos formulários ficou dividida da seguinte forma: 01. Avenida da Independência (05 formulários aplicados); 02. Rua Pedro Velho (04 formulários); 03. Rua 15 de novembro (03 formulários); 04. Rua Gessé Pinto Freire (3 formulários); 05. Rua da Praça da Matriz (03 formulários); 6. Avenida 13 de maio (02 formulários); 7. Rua Adolfo Fernandes (02 formulários) e 08. Rua Quintino Bocaiúva (02 formulários).

Com base nas informações fornecidas pelas entrevistadas nos formulários, as faixas etárias das mulheres são de 19 a 55 anos; sendo das 24 entrevistadas, 11 proprietárias presentes nos estabelecimentos comerciais e 13 gerentes mulheres, presentes nos estabelecimentos comerciais com a mulher proprietária ausente no momento das aplicações dos formulários ${ }^{6}$.

${ }^{6}$ Esta foi uma alternativa para alcançar o número mínimo de entrevistas adotado conforme nossa metodologia.

$\begin{array}{lllll}\text { Caminhos de Geografia } \quad \text { Uberlândia-MG } & \text { v. 21, n. } 76 \quad \text { Ago/2020 } & \text { p. 85-97 } & \text { Página } 94\end{array}$


Infelizmente a presença das proprietárias nos estabelecimentos é mais difícil, tendo em vista que algumas não moram na cidade de Pau dos Ferros, mas em outras cidades no Rio Grande do Norte como, por exemplo, em Mossoró (02), Natal (01) e São Miguel (01), e outras que não residem no Rio Grande do Norte, como as que originam da Paraíba (01) e do Ceará (01), o que ocasiona a ausência das mesmas, deixando a gerente mulher como responsável por toda demanda de vendas e administração do comércio. De acordo com a tabela 02, podemos identificar a tipologia dos estabelecimentos visitados.

Tabela 01 - Pau dos Ferros: ramos de atividade dos estabelecimentos comerciais visitados na pesquisa de campo.

\begin{tabular}{l|c}
\hline Ramos de atividade Econômica & Número de formulários \\
\hline Vestuário e acessórios & 15 \\
\hline Produtos alimentícios & 03 \\
\hline Calçados e acessórios & 02 \\
\hline Artigos para celular & 01 \\
\hline Material de construção & 01 \\
\hline Variedades & 01 \\
\hline Papelaria & 01 \\
\hline Total & $\mathbf{2 4}$ \\
\hline
\end{tabular}

Fonte - Trabalho de campo dos autores, ago., 2019.

Nos formulários também podiam ser identificados o nível de escolaridade das participantes, tendo $01 \mathrm{com}$ nível fundamental II incompleto; 01 com ensino médio incompleto; 11 com nível médio completo; $04 \mathrm{com}$ ensino superior incompleto (cursando ainda) e 07 com ensino superior completo.

O estado civil também perguntado, ficando 07 solteiras, 15 casadas e 02 separadas. Com base ainda no perfil da entrevistada, também foi perguntado se tinham filhos, e 21 entrevistadas responderam que sim, apresentando uma média de 01 a 02 filhos e somente 03 participantes (02 solteiras e 01 casada) responderam que ainda não tinham filhos.

Algumas perguntas, de teor mais pessoal, deixamos as participantes à vontade para responder, resguardando o termo de consentimento ${ }^{7}$. E estas perguntas nos permitiram identificar as duplas e triplas jornadas de trabalho enfrentadas por essas mulheres podendo, a seguir, identificar se existiu alguma dificuldade desde que ingressou no comércio em relação a ser mulher e mãe. Quando perguntado se as mulheres tinham algum tipo de lazer fora do trabalho das responsabilidades domésticas, 07 responderam que não conseguiam ter lazer e 17 responderam que pouco, dificilmente e/ou somente nos dias de domingo.

Com base nas respostas das entrevistadas, na pergunta de qual seria a maior dificuldade encontrada desde sua ingressão na atividade comercial, as respostas variaram: algumas responderam que não tiveram dificuldades, outras encontravam dificuldades em ter alguém para deixar os filhos e a falta de confiança dos fornecedores das mercadorias:

"Percebo a dificuldade de resolver os problemas com os fornecedores dos produtos, quando eles são homens. As vezes quando acontece algum problema com as mercadorias e é necessário realizar a troca, então eu peço para meu esposo falar com eles no meu lugar e, só assim, consigo resolver os problemas da loja. Não sei porque isso acontece, deve ser porque homem passa confiança para homem".

De acordo com as respostas das entrevistadas sobre as dificuldades encontradas em sua atividade, na qual, essas duas respostas, foram ditas por proprietárias com estabelecimento em seu ramo de atividade em vestuários e acessórios, encontramos a presença de um preconceito de gênero bastante latente, que mesmo a mulher sendo proprietária do estabelecimento, sofre preconceito por ser mulher, e esses praticados em sua maioria, pelos homens. Preconceito de gênero enraizado desde muito tempo e que até os dias atuais ainda está presente no cotidiano das pessoas que se inserem nesta atividade.

Somente com o trabalho de campo foi possível observar a nuances das variadas histórias de vida dessas mulheres e identificar as proprietárias desses estabelecimentos comerciais na cidade de Pau dos Ferros.

\footnotetext{
7 Ester termo é exigido pelo Comitê de Ética e foi apresentado no ato da entrevista ao sujeito. Este documento é assinado pelos pesquisadores envolvidos, pelo representante institucional e pelo permitindo ao participante a segurança das informações coletas e de maneira sigilosa.
} 
A abordagem ou a recepção não foi fácil, tanto pela indisponibilidade em responder as questões tão delicadas, quanto pela fidelidade das informações de localização dos estabelecimentos listados pelo cadastro municipal.

Tivemos a dificuldade de entrar no estabelecimento e verificar se o mesmo é liderado por uma mulher. Outra dificuldade encontrada foi a aceitação das mulheres, identificadas nesses estabelecimentos como proprietárias ou gerentes, de aceitar participar da entrevista. Muitas não queriam participar, justificando a perda de tempo no trabalho. Outras evitaram devido não nos apresentarmos como clientes, demonstrando o objetivo de não consumir ou comprar algum produto.

Em alguns momentos, foi necessário a vestimenta do entrevistador mudar e, assim, como estratégia de poder ser mais bem recebido. Dessa forma, percebemos que a maneira que uma pessoa se apresenta vestida, diz muito sobre ela, inclusive, depois que a roupa foi trocada por uma vestimenta mais social.

Outra dificuldade que encontramos foi a localização dos estabelecimentos, tendo em vista que Pau dos Ferros tem a maioria das placas que serviriam para nomear as ruas depredadas ou não haviam mais nenhuma no lugar.

Estas dificuldades relatadas nestes últimos parágrafos consideramos como resultado ou resposta de nossas inquietações originais da pesquisa. O levantamento e análise dos dados primários e secundários foram alcançados, porém, o grande desafio foi a aproximação dos sujeitos da pesquisa em seu ambiente de trabalho.

\section{CONSIDERAÇOES FINAIS}

Pau dos Ferros é uma cidade de caráter regional, que segundo Dantas (2014) e Bezerra (2016) apresentam uma diversidade no setor comercial e na prestação de serviços. Esta cidade se apresenta enquanto um centro de caráter terciário, ou seja, com a concentração dos estabelecimentos comerciais da região, seja em atacado ou varejo.

Este perfil nos mostrou a importância de investigar a atuação da mulher neste setor em Pau dos Ferros. Com isso, concluímos a forte presença da mulher como proprietária de estabelecimentos comerciais nesta cidade, representando $56 \%$ do total em relação aos homens.

O debate sobre a mulher e o comércio, mesmo que não seja tão recorrente para a Geografia, pode ser visto através nesse artigo como uma discussão preliminar que sugere uma maior atenção a evolução da mulher no mercado de trabalho, através das lutas travadas que promovem quebra de paradigmas impostos pela sociedade que se perpetuam até os dias atuais. A luta das mulheres é essencial para a conquista de seus direitos e de sua liberdade de escolha, além da sua independência financeira.

Mulheres que lutaram e lutam pela sua autonomia, conquistam espaço e abrem o seu próprio negócio em busca de sua independência social. Mulheres que inspiram outras mulheres a também realizam o seu sonho de abrirem o próprio negócio.

Que este artigo possa adentrar nesse ramo da pesquisa científica, provocando o debate na Geografia e que o mesmo possa servir de referência para estudos futuros e debates em sala de aula. Que possamos aprofundar e melhorar a metodologia de trabalho com esse tema, que não é fácil, estabelecendo uma agenda de pesquisa futura para uma formação plena e questionadora.

\section{REFERÊNCIAS}

ABRAMO, L.W. A inserção da mulher no mercado de trabalho: uma força de trabalho secundária? 327 f. Tese (Doutorado em sociologia). Universidade de São Paulo. Faculdade de Filosofia, Letras e Ciências Humanas. Departamento de Sociologia. Programa de Doutorado em Sociologia. São Paulo. 2007.

ANDRADE, M. C. de. A questão do território no Brasil. 2. Ed. Hucitec, São Paulo, 2004.

ASSIS, R. H. A inserção da mulher no mercado de Trabalho. Congresso Virtual Brasileiro de Administração. 6. Anais... 2009, p. 01-16.

BARRETO, J. J. Pau dos Ferros: História, Tradição e realidade. CLIMA- Artes gráficas e publicidade Lida. Ribeira, Natal-RN, 1987.

\begin{tabular}{|c|c|}
\hline Caminhos de Geografia & Uberlândia-MG \\
\hline
\end{tabular}


BEZERRA, J. A. A cidade e região de Pau dos Ferros: por uma geografia da distância em uma rede urbana interiorizada. 429 f. Tese (Doutorado em Geografia). Universidade Estadual do Ceará, Centro de Ciências e Tecnologia, Programa de Pós-Graduação em Geografia, Fortaleza, 2016.

CORRÊA, R. L. O Espaço Urbano. São Paulo: Ática, 1989.

DANTAS, J. R. Q. As cidades médias no desenvolvimento regional: um estudo sobre Pau dos Ferros (RN). 260 f. Tese (Doutorado em Ciências Sociais). Universidade Federal do Rio Grande do Norte. Centro de Ciências Humanas, Letras e artes. Programa de Pós-Graduação em ciências Sociais. Natal, RN. 2014.

FERREIRA, A. C; BEZERRA, J. A. O comércio moderno na cidade: as mudanças nas relações do setor calçadista em Pau dos Ferros (RN). $21 \mathrm{f}$. Trabalho de Conclusão de Curso (Graduação em Geografia). Universidade do Estado do Rio Grande do Norte. 2017.

GOLDENBERG, M. A arte de pesquisar: como fazer pesquisa qualitativa em Ciências Sociais. Rio de Janeiro/São Paulo: Editora Record, 1997.

GONÇAVES, L. C.; MIRANDA, D. F. Estudo da evolução do trabalho da mulher e a sua valorização no mercado de trabalho. Revista. Faculdade Montes Belos, v. s, n. 1. Mar. 2012.

IBGE. Instituto Brasileiro de Geografia e Estatística. Cidades@. Disponível em: <https://ibge.gov.br/>. Acesso em: 20 ago., 2019.

MUMFORD, L. A cidade na história: suas origens, transformações e perspectivas. Tradução: Neil R. da Silva. 4 ed. São Paulo: Martins Fontes, 1998.

OLIVEIRA, A. C. M. A evolução da mulher no Brasil do período da Colônia a República. Instituto Federal de Sergipe, São Cristóvão - SE, 2012.

PAIVA, L. U. S.; BEZERRA, J. A. O comércio e o consumo urbanos: novas formas de representação da cidade de Pau dos Ferros. Anais... Semana de Ciência, Tecnologia e Inovação da UERN. 14. PróReitorias de Pesquisa e Pós-Graduação/UERN. Mossoró, RN, 2018. p. 687-690.

PINTAUDI, S. M. A cidade e as formas do comércio. São Paulo: Contexto, 2002. p. 143-158.

RODRIGUES, V. L. A importância da Mulher. Disponível em: <http://www.diaadiaeducacao.pr.gov.br/portals/pde/arquivos/729-4.pdf > Acesso em 19 Jul. 2019.

ROSSINI, R. E. Nas atividades econômicas a modernidade tecnológica exclui homens e mulheres. incorpora mais a mulher na cidade e menos no campo. In: GEOUSP - Espaço e Tempo, São Paulo, № 12, p. 47- 56, 2002. DOI: https://doi.org/10.11606/issn.2179-0892.geousp.2002.123771

SALGUEIRO, B. T.; CACHINHO, H. As relações cidade-comércio: dinâmicas de evolução e modelos interpretativos. Rio de Janeiro, 2009. p. 9-39.

SILVA, C. H. C. Estudos sobre o comércio e o consumo na perspectiva da geografia urbana. Florianópolis, 2014a, p. 149-178.

SILVA, F. de S. B. O "ser" vendedor no comércio de rua em Pau dos Ferros/RN: expressões da informalidade na via pública. In: Geotemas. Pau dos Ferros, Rio Grande do Norte, Brasil, v 4, n. 1, p. 3-13, jan./jun., 2014b. DOI: https://doi.org/10.33237/geotemas.v4i1.1202

Recebido em: 11/11/2019

Aceito para publicação em: 30/06/2020 